\title{
O cuidar de uma criança com diabetes mellitus tipo 1: concepções dos cuidadores informais
}

\section{Taking care of children with type 1 diabetes mellitus: informal care-takers' ideas}

\section{El cuidar de un niño con diabetes mellitas tipo 1: concepciónes de los cuidadores informales}

\author{
Catarina Aparecida Sales', Nayara Mizuno Tironi", Eloana Ferreira D'Artibale ${ }^{\prime \prime \prime}$,
}

Maria Aparecida Pinheiro da SilvalV, Mara Rúbia Violin`, Bruna Corrêa Castilho VI

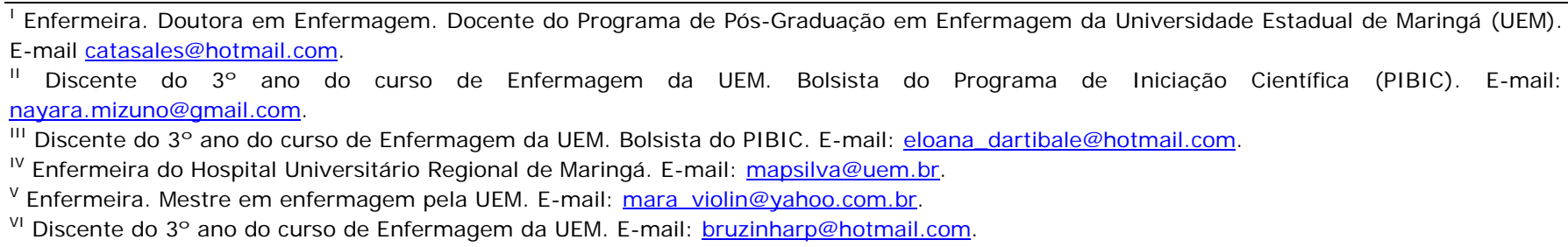

\section{RESUMO}

O Ministério da Saúde define Diabetes mellitus como síndrome de etiologia múltipla, decorrente da falta da insulina e/ou da incapacidade da insulina exercer adequadamente seus efeitos. Essa doença vem apresentando incidência com proporções cada vez maiores em nosso meio. Assim, nesse estudo, nosso objetivo foi compreender os sentimentos suscitados pelos cuidadores informais que cuidam de crianças menores de 12 anos com Diabetes mellitus tipo 1. Para tanto, optamos por um estudo qualitativo, embasado nos princípios da fenomenologia existencial. A pesquisa foi realizada em uma cidade do Noroeste do Paraná, nos meses de junho e julho de 2007. Os seis entrevistados foram inquiridos com a seguinte questão: “O que significa para você cuidar de uma criança diabética?". Da análise emergiram quatro categorias: descobrindo o diagnóstico do filho; convivendo com a doença; vivenciando a necessidade de compartilhar seu pesar e; a importância da espiritualidade para o entendimento da situação. Depreendemos que vivenciar esta situação é um fardo difícil de ser abarcado pelos cuidadores e que o impacto da doença pode causar crises de adaptação no enfrentamento da família. Portanto, devemos estar atentos ao modo como o portador de diabetes e seus familiares sentem, enfrentam e interpretam o diabetes e seu tratamento.

Descritores: Diabetes mellitus tipo 1; Cuidado da criança; Acontecimentos que mudam a vida; Cuidadores.

\section{ABSTRACT}

The Health Ministry defines Diabetes mellitus as a multiple etiology syndrome caused by lack of insulin and insulin incapability to achieve result. This pathology is acquiring increasingly greater proportions among the population. Current analysis investigates the feelings presented by informal care-takers that attend less than 12 years old children with Type I Diabetes mellitus. A qualitative study, based on the principles of existential phenomenology, has been undertaken in a town in the northwestern region of the state of Paraná/Brazil, during June and July of 2007. The six interviewed people were asked the following question: "What does it mean for you to take care of a diabetic child?" Four categories were revealed: discovering the child's diagnosis; living with the disease; experiencing the need to share suffering; the importance of spirituality to understand the situation. The experiencing of such situation is a difficult burden for those who take care of patients and the impact caused by the disease may bring about adaptation crises within the family. Results show the importance of being aware how the diabetic person and his/her relatives feel, facing and interpreting diabetes and its treatment.

Descriptors: Diabetes Mellitus type 1; Child care; Life Change Events; Caregivers.

\section{RESUMEN}

El Ministerio de la Salud define Diabetes mellitus como síndrome de etiología múltipla, consecuencia de la falta de insulina y/o de la incapacidad de la insulina ejercer adecuadamente sus efectos. Esa patología viene presentando una incidencia con proporciones cada vez más grandes en nuestro medio. Así, en ese estudio, nuestro objetivo fue comprender los sentimientos suscitados por los cuidadores informales que cuidan de niños menores de 12 años con Diabetes mellitus tipo 1. Para tanto, optamos por un estudio cualitativo, embasado en los principios de la fenomenología existencial. La investigación fue realizada en una ciudad del Noroeste de Paraná, en los meses de junio y julio de 2007. Los seis entrevistados fueron encuestados con la siguiente cuestión: “¿Qué que significa para usted cuidar de un niño diabético?". Del análisis se apuntó cuatro categorías: Descubriendo el diagnóstico del hijo; Conviviendo con la enfermedad; Vivenciando la necesidad de compartir su pesar y; La importancia de la espiritualidad para el entendimiento de la situación. Sacamos la lección que vivenciar esta situación es una carga difícil de ser abarcada por los cuidadores y que el impacto de la enfermedad puede causar crisis de adaptación en el enfrentamiento de la familia. Por lo tanto, debemos estar atentos al modo como el portador de diabetes y sus familiares sienten, enfrentan e interpretan la diabetes y su tratamiento. 
Descriptores: Diabetes Mellitus Tipo 1; Cuidado del Niño; Acontecimientos que Cambian la Vida; cuidadores. 


\section{NTRODUÇÃO}

O conhecimento do Diabetes mellitus é muito antigo, datando já da época dos egípcios (1500 a.C.) que descreviam a doença como associada com a produção de grande quantidade de urina. Esta condição passou a ser considerada como doença por Celsus (30 a 50 d.C.) e, somente dois séculos após, foi denominada como Diabetes por Aretaeus da Capadócia. A condição doce da urina surge registrada nos Vedas, livros sagrados da Índia e, somente em 1.674, Willis a descreve como "se a urina fosse embebida com mel e açúcar", estabelecendo assim o nome Diabetes mellitus (mellitus significa mel) ${ }^{(1)}$.

Esta doença tem como denominador comum o aumento de glicose no sangue, decorrente, na maioria das vezes, de produção diminuída ou alterada de insulina pelo pâncreas. É classificada em dois tipos, considerados os mais frequentes: o tipo 1 ou insulinodependente (DMID), e o tipo 2 ou nãoinsulinodependente (DMNID), sendo este mais prevalente na população adulta e idosa. Porém, acomete pessoas das mais variadas faixas etárias, independentemente de sexo, cor ou condições socioeconômicas ${ }^{(2)}$.

O Ministério da Saúde define o Diabetes mellitus como um grupo de doenças metabólicas caracterizadas por hiperglicemia e associadas a complicações, disfunções e insuficiência de vários órgãos, especialmente olhos, rins, nervos, cérebro e vasos sanguíneos. Pode resultar de defeitos de secreção e/ou ação da insulina que envolvem processos patogênicos específicos, por exemplo, destruição das células beta do pâncreas (produtoras de insulina), resistência à ação da insulina, distúrbios da secreção da insulina, entre outros. Essa doença vem apresentando incidência com proporções cada vez maiores em nosso meio. Calcula-se que, em 2025, atinja $5,4 \%$ da população adulta mundial. A maior parte desse aumento se dará em países em desenvolvimento, acentuando-se nesses países, o padrão atual de concentração de casos na faixa etária de 45-64 $\operatorname{anos}^{(3)}$.

No que se refere ao Diabetes tipo 1, a Sociedade Brasileira de Diabetes aponta que a cada ano, mais de 70 mil crianças desenvolvem a doença e, no mundo, esse valor passa para 440 mil. A taxa de aumento de Diabetes tipo 1 , nas crianças, é de $3 \%$ ao ano e atualmente, mais de 200 crianças desenvolvem tal doença a cada dia(2).

O Diabetes mellitus do tipo 1 é caracterizado pela destruição das células beta pancreáticas. Acredita-se que uma combinação de fatores genéticos, imunológicos e possivelmente ambientais (ex: virais) contribua para destruição das células beta $^{(2)}$.

A morbidez associada com diabetes de longa duração de ambos os tipos resulta de certas complicações, tais como microangiopatia, retinopatia, nefropatia e neuropatia. Se não houver controle metabólico adequado, poderá haver complicações em longo prazo, podendo haver sequelas como amputação, cegueira, retinopatia, nefropatia, dentre outras consequências que iriam comprometer a qualidade de vida dessas pessoas. Consequentemente, a base dessas complicações crônicas em longo prazo, é assunto de muita pesquisa. O diabético sofre com as manifestações clínicas da doença como a poliúria, polidipsia, polifagia, perda de peso e astenia(2).

Todo comprometimento fisiológico, a nosso ver, manifestado em doentes diabéticos adultos, também é vivenciado por crianças diabéticas, pois o seu convívio social e familiar é afetado, uma vez que este passa a fazer parte de uma rotina de aplicações insulínicas, educação alimentar, prática de exercícios físicos constantes, controle glicêmico e conscientização sobre sua condição fisiológica. Outro aspecto verificado em nossa experiência diz respeito à dificuldade da criança em aceitar sua condição existencial, uma vez que esta lhe desperta sentimento de revolta, que a faz sentir-se diferente de outras crianças.

Em nossa vivência com crianças diabéticas, observamos que a rotina da vida familiar é alterada com relação aos cuidados e ao controle, pois toda a família tem de se adaptar com rotina diferenciada frente à situação de ter um filho com necessidades especiais, as quais eles participam ativamente. Para Silva ${ }^{(4)}$, os pacientes diabéticos têm sentimento de inferioridade pelos cuidados constantes exigidos para controlar a doença. E o controle do Diabetes é muito intenso e chega a classificar a criança diabética como escrava de seu tratamento ${ }^{(5)}$.

Quando os familiares descobrem tal doença em seus filhos, defrontam com dúvidas, incertezas, revoltas e desespero e acabam por buscar explicações para entenderem melhor essa complicação, assim como também soluções para que possam minimizar o sofrimento e efeitos que possam vir a aparecer. Estes familiares são os denominados cuidadores informais.

Diante do exposto, ao cuidar de uma criança diabética, o cuidador informal transmite o quão é difícil ter um filho diabético. Não obstante, as necessidades desses seres não são observadas pelos profissionais de saúde, que se restringe apenas ao cuidado técnico, não se preocupando com os aspectos emocionais e psicológicos vivenciados por esses cuidadores.

Depreendemos que os profissionais de saúde reconhecem a tênue situação em que se encontram os diabéticos, mas ainda, é preciso reconhecer também a situação dos cuidadores destes diabéticos. E são eles, os cuidadores, os sujeitos desse estudo, 
mas, vale acrescentar que nossa experiência com estes nos mostra que nem sempre é possível, por fatores práticos e profissionais, compreender os sentimentos avivados nesses seres em virtude da condição existencial de outro ser querido e próximo.

Por este contexto, definimos como objetivo do estudo compreender os sentimentos desses seres em relação à sua condição. Acreditamos que os resultados possibilitarão aos profissionais ajudar estes indivíduos a resgatarem seu próprio valor moral enquanto seres-no-mundo, visando sempre atendêlos e prepará-los para enfrentar suas condições existenciais, construindo seu viver autêntico, e, principalmente, obter, por meio de seus discursos, luz para direcionar nossas ações no sentido de transformar a realidade vivenciada por eles.

\section{O CAMI NHO METODOLÓGI CO}

Para este estudo, optamos pela pesquisa qualitativa numa abordagem fenomenológica existencial heideggeriana. O método fenomenológico coloca como ponto de partida de sua reflexão aquele ser que se dá a conhecer imediatamente, ou seja, o próprio homem, colocando-o dentro de uma dimensão ontológica. A fenomenologia existencial heideggeriana possibilita a compreensão do ser, pois ele é aquilo que se oculta naquilo que se manifesta por meio da linguagem ${ }^{(6)}$.

O modo de existir do homem é único entre todos os seres existentes, ele é único por possuir consciência e por não poder se dissociar do mundo em que é concebido. Não há sentido em descrever o homem como um ser fora do mundo e também sem considerar a sua finitude, pois a presença do homem no mundo real e a morte são imprescindíveis à sua condição de ser humano. A fenomenologia existencial heideggeriana, "descreve as condições da existência que incluem o poder de fazer escolhas nos limites da facticidade humana e dos modos factuais de existir. Essa descrição torna o ser humano capaz de analisar, explicar, julgar e refletir sobre suas experiências

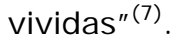

A pesquisa foi realizada em uma cidade do Noroeste do Estado do Paraná. Foram entrevistados seis cuidadores informais que cuidavam de filhos menores de 12 anos portadores de Diabetes mellitus tipo 1, e frequentavam a ADIM - Associação dos Diabéticos de Maringá nos meses de junho e julho de 2007. A faixa etária foi determinada conforme a Lei n॰ 8.069, de 13 de julho de 1990 que dispõe o seguinte no Art. $2^{\circ}$ do Estatuto da Criança e do adolescente: "Considera-se criança, para os efeitos desta lei, a pessoa até 12 anos de idade incompletos e adolescentes entre 12 e 18 anos de idade"(8).

Durante nossos encontros com os cuidadores na ADIM, explicamos a finalidade do estudo e solicitamos sua colaboração. A partir da permissão dos cuidadores, iniciamos a coleta de dados, a qual foi realizada no domicílio de cada família com o intuito de captar seus sentimentos, como também, a expressão corporal deles durante a entrevista. Para tanto, utilizamos gravador e a observação.

A nosso ver, a descrição de suas experiências deve envolver pensamentos, sentimentos e ações sobre a realidade vivida. Nesse sentido, inquirimos os informantes com a seguinte questão norteadora: "O que significa para você cuidar de uma criança diabética?". Para manter o anonimato dos mesmos, referenciamos-lhes de cuidadores informais $(\mathrm{Cl} 1, \mathrm{Cl} 2, \mathrm{Cl} 3 \ldots)$; quanto às crianças, quando citadas nos depoimentos, com nomes de personagens de histórias em quadrinhos.

Para captar a plenitude expressa pelos sujeitos em suas linguagens, optamos pela análise individual de cada discurso. Assim, a priori, realizamos leituras atentas de cada depoimento, separando os trechos ou unidades de sentidos (us) que para nós se mostraram como estruturas fundamentais da existência. A posteriori, passamos a analisar as unidades de sentido de cada depoimento, realizando seleção fenomenológica da linguagem de cada sujeito, pois uma unidade de sentido constitui-se, em geral, de sentimentos revelados pelos depoentes que contemplam a interrogação ontológica ${ }^{(9)}$.

Por se tratar de uma pesquisa que envolve seres humanos, observamos aspectos éticos disciplinados pela Resolução 196/96 do CNS - MS. A solicitação de participação no estudo se fez acompanhar de duas vias do Termo de Consentimento Livre e Esclarecido. Nesta solicitação, notificamos sobre as finalidades da pesquisa, tipo de participação desejada e tempo provável de duração da entrevista. Asseguramos também aos partícipes a desvinculação entre a pesquisa e o atendimento prestado pelos serviços de saúde; o livre consentimento e a liberdade de desistir do estudo, se em qualquer momento assim desejassem, garantimos também, o sigilo quanto às informações prestadas e anonimato sempre que os resultados forem divulgados. Esclarecemos que as entrevistas ocorrerão após a aprovação Comitê Permanente de Ética em Pesquisa envolvendo seres humanos da Universidade Estadual de Maringá (Parecer n. ${ }^{\circ}$ 115/2007).

\section{RESULTADOS E DI SCUSSÃO}

Dos sentimentos suscitados, emergiram quatro temáticas existenciais que foram interpretadas a partir de algumas ideias de Martin Heidegger: descobrindo o diagnóstico do filho; convivendo com a doença; vivenciando a necessidade de apoio; a importância da espiritualidade para o entendimento da situação. 


\section{Descobrindo o diagnóstico do filho}

$\mathrm{Na}$ concepção heideggeriana, o termo existência designa o processo de abertura do ser humano consigo mesmo e com o mundo e, nessa existencialidade, ele planeja seu próprio porvir, isto é, planeja sua história no mundo, imaginando um futuro feliz para si e sua família. Nesse sentido, negligencia as possibilidades existenciais impostas pela própria condição humana, ou pelo espaço mundano que é lançado ${ }^{(6)}$.

Não obstante, estando no mundo, o homem não se relaciona somente com os instrumentos necessários à sua sobrevivência, mas também se abre a outros entes. Nessa abertura, o ser-no-mundo busca, na afetividade de outro Ser-aí, construir sua história familiar, ou seja, compartilhar com o outro o seu existir no mundo. A partir dessa união, o homem e a mulher vislumbram a possibilidade de ter filhos, para dar continuidade à sua história. Para a mulher, vivenciar a gestação é planejar um desenvolvimento saudável para seu filho ${ }^{(10)}$.

Esse processo de abertura da mãe em relação ao filho desenvolve-lhe o sentimento de que o filho é parte de seu próprio corpo, isto é, faz parte de seu poder-ser e está desde sempre inserido em sua existência. Na fala do cuidador 5 , notamos seu pesar perante a facticidade da filha que ela moldou em seu ventre.

[...] Na hora que eu abri o exame, eu já vi que era diabetes, na mesma hora corri ao médico levando os exames, pedi para ela ser internada, para avaliar e fazer novos exames e para mim foi uma decepção muito grande, uma coisa que jamais esperaria de uma filha. Eu me apavorei, fiquei assim que nem piscava. Aquilo foi a mesma coisa que você me jogar um balde de água quente, aquilo eu estava assim me derretendo. Para mim era o fim do mundo, jamais a gente vai aceitar uma doença na família, ainda mais em uma filha que a gente gerou. $(\mathrm{Cl} 5)$

Atentando às falas de outros cuidadores, percebemos que eles expressam sentimentos de desabrigados, completamente perdidos e desorientados ao descobrirem que seu filho era diabético, condição essa, que Ihes aviva sentimentos de revolta, incompreensão, preocupação com a doença do filho e, principalmente, sentimentos de culpa ante sua insipiência em relação aos cuidados necessários ao filho.

Para mim foi horrível no dia, eu chorei, eu até liguei para o pai em São Paulo na casa dele, ele chorava, chorava, ele não entendia. Foi à mesma coisa que o chão abrir. No começo era uma correria, a gente levava-o três vezes por dia no postinho e a gente também era principiante, então se estava baixo a gente já corria, se estava alta a gente corria. Com essa doença do Cebolinha, ele acabou pedindo as contas do serviço lá por que ele não conseguia mais trabalhar, porque ele só ficava preocupado, por que era muita correria com o Cebolinha aqui. ( $\mathrm{Cl} 1)$. [...] E já constatou que a glicemia estava muito alta, $275 \mathrm{mg} / \mathrm{dl}$ em jejum, no outro dia a gente já levou ele no médico e ele estava com a glicemia em $450 \mathrm{mg} / \mathrm{dl}$ e ai foi internado e, ficou três dias no hospital e eu já quase morri de tanto desgosto lá porque eu não sabia nada sobre diabetes infantil, não entendia muito bem, fui obrigada a aplicar injeção nele e eu não sabia direito e ele começava a chorar muito desesperado. Eu choro muito a noite, penso porque aconteceu isso comigo, se não tem ninguém da família. ( $\mathrm{Cl} 3)$

$\mathrm{Na}$ meditação heideggeriana, a existência humana pode tornar-se digna de questionamento, principalmente quando o ser humano experiencia alguma facticidade em seu cotidiano, a qual não consegue abarcar de imediato e, nesses momentos, o ser-no-mundo se fecha em si mesmo, não conseguindo entender sua condição existencial, negando a si mesmo a verdade que se descortina ao seu redor ${ }^{(6)}$. Nessa perspectiva, distinguimos que os cuidadores, em suas linguagens, exprimem o quão é difícil aceitarem a doença dos filhos, demonstrando certa negação de sua condição existencial.

[...] No começo a gente ficou revoltado, por que que ele teve? Por que com ele? Por que que aconteceu com a gente? A gente não fazia nada de errado, fazia tudo certo e ter acontecido com ele. O chão caiu! Pensei que eu tinha caído num buraco e não sabia nem que estava fazendo, não enxergava nada na frente. A gente não sabia o que fazer, não dormia a noite nem eu, nem minha esposa preocupada, você perde a noção de tudo, você não acredita, assim não é verdade, não é verdade. $(\mathrm{Cl} 2)$

[...] Eu ficava à noite com ela no hospital e o pai durante o dia, de manhã vinha para casa dormir e não conseguia, pois, ficava pensando, por que meu Deus tinha que ser com a minha filha? Por que a minha filha tinha que ter esta doença, o que eu vou fazer? O que é isso? Por que as coisas acontecem com os outros, mas com a gente achamos que nunca vai acontecer? Sabe é muito difícil para a gente, porque não temos nenhum diabético na família. $(\mathrm{Cl} 4)$

O comportamento destes cuidadores pode ser examinado como um grito de inautenticidade, do não-assumir-se nas suas possibilidades de estar-aí com uma criança diabética, é um modo de ser que não está fundado no seu sentido originário de possibilidade pura. "A revolta e a negação são manifestadas quando se negligencia o tratamento, ignorando possíveis complicações. Sentimentos como tristeza, depressão, invasão, revolta e negação emergem da condição crônica e da gravidade apresentada pela doença. Situações em que se intercalam com momentos de aceitação, otimismo e esperanças positivas, colocando em evidencia o lado 
positivo e negativo do diabetes que oscila contraditoriamente"(5).

\section{Convivendo com a doença}

No cotidiano de nossas vidas, amiúde, experimentamos sentimentos de natureza e intensidade variados que veem ao nosso encontro, decorrentes de nossa própria condição de estar lançado-no-mundo. São situações que causam temor sem, contudo, ter a explicação para elas. "São estados afetivos que nos colocam diante da desnudez de nossa condição original, ou seja, de nossa condição de ser humano"(11).

É nesse estado que o ser humano compreende suas experiências, ou seja, atribui significados e sentidos próprios aos objetos em seu mundo, dando assim sentido à sua existência. Neste prisma, os utensílios ou objetos não são uma realidade simplesmente subsistente, mas está fundamentalmente disponível para um uso determinado. O utensílio é essencialmente alguma coisa que o homem dispõe para viver ${ }^{(6)}$. Neste entender, notamos em algumas falas, que apesar de os cuidadores terem consciência da importância do dispositivo de glicemia para a manutenção da saúde de seus filhos, os mesmos demonstram tristeza ao utilizá-lo em seu ente querido, como se sentisse a dor dos filhos em seus próprios corpos, assim, eles buscam formas compensativas para diminuir 0 sofrimento deles.

[...] O Cebolinha já teve várias crises, teve uma que estava eu e o pai dentro de casa, ele estava desmaiado no colo do pai, minha mãe pegou o carro e levamos para o hospital, eu nem esperei e já entrei direto, estava alta, enfiaram o soro e deram não sei mais o que, e ficou lá em observação um dia e meio, até normalizar, ele toma insulina de manhã e a tarde, a NPH e a regular, ele toma as duas, faz com a seringa porque com essa caneta não dá, porque com ela tem que furar duas vezes, porque não pode misturar ela na caneta, você tem que por uma e depois por a outra, e a gente acha muita judiação porque ele não gosta de ser furado nem uma vez imagina ter que ser furado duas vezes de manhã e duas vezes de tarde. Dá tristeza, mas a gente procura dar tudo, se mata de um jeito se mata do outro porque ele às vezes até quer um pouco mais do que as outras crianças. É muito difícil a gente negar alguma coisa para ele, por causa dessa situação ele acabou sendo mais mimado, por todos. ( $\mathrm{Cl} 1)$

[...] E eu também não conseguia fazer insulina nela, não conseguia fazer. Ver aquelas unidades ter que fazer toda hora o exame de dedinho, meu Deus mais toda hora isso? ( $\mathrm{Cl} 5$ )

Refletindo sobre os sentimentos explanados pelos cuidadores, apreendemos que cuidar de um filho diabético é uma situação difícil de ser abarcada, “as mães não tem apoio e suporte para enfrentar tais situações no dia-a-dia e, conseqüentemente, desenvolvem sentimentos de culpa e superproteção"(12). Além desses sentimentos, brota também o sentimento de sofrimento, pois a insulinoterapia limita e restringe muito a vida dos familiares $^{(13)}$.

Em outras linguagens, observamos que ter dado existência a um filho diabético aviva nos cuidadores sentimentos de temor e preocupação, sentimentos que os faz esquecer, de certa forma de si mesmos e, dedicar-se ao filho. E, esse laço de afetividade sensibiliza também outros entes no seio familiar, principalmente, no que se refere ao cuidado com uma alimentação adequada ao diabético. Não obstante, ao analisarmos as linguagens a seguir; podemos distinguir que a doença que trouxe tanta dor, despertou- Ihes hábitos saudáveis de vida.

[...] A gente cuida mais dele do que de nós praticamente. Só ele é diabético! Na alimentação ele come pouco, não come muito, açúcar aqui em casa acabou. Açúcar não tem nada, só quem toma é a minha esposa para fazer um pouco de café, mas o resto é tudo sem açúcar, ele mesmo lê quando tem açúcar e, ele não come. Come bastante fruta também. Salada que ele não come muito, mas a nutricionista falou que tem que comer bastante. Até nós aqui mudamos também o nosso hábito. Muita coisa que a gente comia aqui era porcaria hoje estamos comendo muito mais coisas saudáveis. Não só aqui, até na minha mãe também, ela já mudou um pouco. Com o passar do tempo nós já fomos acostumando, já assimilando isso. Aquela revolta já foi diminuindo um pouco, porque é revoltante. $(\mathrm{Cl} 2)$ [...] E o que ela puder a gente pode e o que ela não puder a gente também não pode, então aqui em casa nós todos somos diabéticos, a gente trabalha para ela, tudo que eu posso eu faço e ela sabe disso. ( $\mathrm{Cl} 5$ ) [...] Para comprar as coisas era complicado, coisas de comer era mais caro, hoje já é mais acessível, mais ainda continua caro. Com o tanto de diabetes que tem no país eu acho tudo muito caro. Eu tenho medo de se não seguir as dietas direito, porque pode ter conseqüências, tem gente que fica cego, perde dedo, corta a perna. É complicado, é uma doencinha chata, você tem que ficar vigiando o tempo inteiro, come um negócio, pode subir, apesar de tudo o que a gente come vira açúcar. Eu procuro não comprar refrigerante, a gente já passou tudo para zero, bolacha não compro muito, quando compro, compro diet. ( $\mathrm{Cl} 6)$

A respeito dos sentimentos narrados pelos cuidadores, podemos entender que mudar comportamentos em relação à dieta de criança e adolescente passa, obrigatoriamente, pela educação do grupo familiar ${ }^{(12)}$. A reestruturação alimentar é uma das coisas mais difíceis de inserir na nova 
rotina, pois todos estavam acostumados a ingerir todo tipo de alimento sem restrição, portanto, a mudança na rotina da família acaba sendo inevitável e radical. Alguns alimentos são proibidos ou restritos, outros são adaptados, e há também os que são inseridos ao hábito alimentar, sendo necessário maior rigor nos horários das refeições ${ }^{(13)}$.

Neste contexto, a obtenção de uma dieta equilibrada e satisfatória depende da ingestão de vários nutrientes, que são oferecidos naturalmente por meio dos alimentos. A liberação dos carboidratos no plano alimentar permite manter uma oferta menor de lipídeos, de forma que estes venham a complementar a necessidade energética e desempenhar suas funções orgânicas mais específicas, como transporte de vitaminas lipossolúveis $(A, D, E, K)$, e como fontes importantes de ácidos graxos essenciais ${ }^{(14)}$. Assim, apercebemos na fala do cuidador 4, que a falta de orientações relativas aos alimentos, gera-lhe sentimentos de apreensão e culpa após um pequeno esquecimento.

[...] Outro dia o pai deixou três bolinhos de queijo no microondas, e foi mexer na construção, e ela comeu os três, o pai percebeu o nervosismo dela e foi fazer o teste, estava em $420 \mathrm{mg} / \mathrm{dl}$, ai aplicou a insulina o pai disse: eu fiquei meio desesperado porque achava que eu não estava cuidando direito, porque na verdade nós não temos muita orientação. Apesar que tudo isso é só o começo, que por ela não conhecer muito os sabores das coisas, fica até fácil da gente controlar. A Magali com três anos e seis meses nunca chupou um sorvete. $(\mathrm{Cl} 4)$

[...] Ele queria morrer, e eu também queria morrer de tanto desgosto por não saber cuidar dele. De repente ele pegou uma faca e começou a ameaçar que criança que é doente é porque Deus não gostava. Eu fiquei desesperada e procurei ajuda na associação dos diabéticos. ( $\mathrm{Cl} 3$ )

$\mathrm{Na}$ analítica existencial heideggeriana, o medo ou temor é investigado como um dos modos que o Dasein se expressa ao mundo em seu ter-sidolançado. O medo é examinado como um sentimento inquietante ante uma situação desconhecida, que inesperadamente o ser humano tem que enfrentar, gerando-lhe sensação interior de agonia(6). Nesse pensar, na interlocução do cuidador 3, é manifestada a agonia que invadiu sua alma ao sentir o desespero do filho perante a doença. Entretanto, na sequência de sua fala, o entrevistado transmite que apesar de a angústia provocar-lhe sensações desagradáveis perante a atitude de seu ente querido, encontra forças em si mesmo para controlar a situação. Assim, busca apoio em outros entes.

O Ser-aí, em sua transcendência, pode ter atitudes distintas para se apropriar do mundo ao seu redor. O termo, nessa conotação, indica estado existencial e pessoal. Nesse contexto, distinguimos, nas unidades a seguir que os cuidadores procuraram antecipar as suas próprias possibilidades, tentando agarrarem-se à sua situação, não com desânimo, mas com esperança de aprender a cuidar melhor do filho. Dessa forma, eles tentam superar sua própria angústia, manifestando 0 seu poder de transcendência sobre o mundo, e sobre si mesmo, projetando um sentido em seu existir-no-mundo. E, essa possibilidade de vislumbrar um porvir melhor para seu ente querido é manifestada quando os entrevistados explanam.

[...] Eu até pensei em fazer um curso de auxiliar de enfermagem só para aprender mesmo, por causa dele disseram que não precisa, que é simples, mais às vezes a gente dá uns gafes feios, às vezes fica roxinho. Tudo que a gente faz é mais no tato. $(\mathrm{Cl} 1)$

Em relação à busca de conhecimento examinamos também que alguns cuidadores transmitem certo otimismo acerca dos estudos realizados na área, vislumbrando esperança quanto à possibilidade de cura para seus filhos.

[...] Eu acho que ainda vai ter cura, tem muitos estudos em relação a isso, como as células-tronco. Eu acho que logo já vai ter alguma coisa sim. Eu creio que logo vai ter, mas até que o dia não chegue a gente vai controlando. Esses dias está controlado, mas tem dia que dá uma alteradinha. $(\mathrm{Cl} 2)$

[...] Hoje eu estou melhor, aprendi mais, também leio bastante revista. Aprendi mais, mas nunca deixa de ser assim uma preocupação constante, nunca deixa de ser um tormento. Porque a gente não pode descuidar. Eu cuido dele toda hora, mas às vezes, eu fico preocupada de quando ele ficar mais adulto, ele não querer ajuda e não se ajudar. $(\mathrm{Cl} 3)$

Visualizamos, ainda que, no final de sua linguagem, o cuidador 3 exprime que, ter um filho diabético na família, pode experienciar sentimentos de incerteza quanto ao presente e futuro de seu familiar, sentimentos que envolvem as suas próprias perspectivas de vida. E, além de vivenciar as intercorrências junto aos seus filhos, os pais (cuidadores) sofrem por imaginar como será o porvir destes, fazendo com que desejem não somente o controle da doença, mas, sobretudo a descoberta da cura, para amenizar o sofrimento do filho(14).

[...] Tem hora que acostuma fazer insulina, mais o bom era se tivesse cura, que nem eu estava conversando com o doutor ele falou que daqui uns dez anos, com as células-tronco. ( $\mathrm{Cl} 6)$

Em sua vivência cotidiana com a doença, os cuidadores aludem também em se preocuparem com o aprendizado do filho, uma vez que temem que o filho apresente episódios de hipoglicemia na escola e, os professores não estejam preparados adequadamente para implementar os cuidados necessários. 
[...] Chegou uma certa idade que ela começou a ir pra escola ai a gente avisa na escola que ela tem diabetes, e era muito instável a diabetes dela, subia e descia, dava muito hipoglicemia, até acertar a dose da insulina. ( $\mathrm{Cl} 6)$

Em relação ao sentimento exposto pelo cuidador, os resultados apresentados por outras pesquisadoras reforçam seu pensar: "As dificuldades relacionadas às atividades escolares foram manifestadas por 9 $(30,0 \%)$ das mães, que referiram perceber prejuízos no processo educacional do filho, relatando sentiremse também inseguras e com medo do filho apresentar episódios de hipoglicemia na escola, acreditando que os professores não estão preparados para socorrê-los nesta situação"(12).

Acerca questão, a literatura internacional recomenda ações preventivas que podem contribuir para o bem estar da criança diabética, entre elas a importância da escola fornecer treinamento para todos os adultos que educam ou cuidam dos alunos sobre os sintomas e tratamento da hipo e hiperglicemia e outros procedimentos de emergência, tais como: 1) fazer glicemia capilar anotando e monitorando os resultados; 2) tomar as ações necessárias para os níveis de glicose fora do normal conforme indicado no Plano de Cuidado de Diabetes do aluno; 3) testar a urina e sangue para cetonas, quando necessário e ser responsável pelos resultados destes exames ${ }^{(15)}$.

O Diabetes mellitus acarreta mudanças significativas na relação que o doente estabelece com o mundo que o cerca. Neste sentido, percebemos no tom de voz do cuidador que o mesmo exprime tristeza ao relatar o viver ambíguo de seu ente querido, pois se de um lado a medicação auxilia no controle da doença, por outro lado despertam em outros entes manifestações de discriminações, situações essas, que avivam na criança sentimentos de negação e recusa em administrar a insulina.

[...] Ela não aceita e fala que o povo tira sarro. O povo tem até hoje preconceito, ela se recusa, ela faz mesmo na marra, a gente pega ela, e faz, se dependesse dela ela não faria. Ela levaria uma vida normal como se não tivesse nada. (Cl6)

Com relação à discriminação, seja ela na escola ou no trabalho, percebemos que os governantes estão tomando providências, pois já há legislações favoráveis ao portador de diabetes. Segundo a Constituição Federal, o artigo 3o, inciso IV prevê o bem-estar de todo cidadão, sem distinção de sexo, raça, cor, origem e quaisquer outras formas de discriminação e prevê no inciso XLI, punição para qualquer discriminação atentória aos direitos e liberdades fundamentais. Sendo assim, a Lei 9.029/95 veda qualquer medida discriminatória e limitativa para fins de acesso e manutenção da relação de emprego, não importando se o cidadão tem ou não diabetes. Já no Estado de São Paulo, há duas leis estaduais, a Lei no 11.369 e a Lei no 11.370, ambas de 28/03/2003, que passaram a vigorar no Estado no ano passado. A primeira veda qualquer forma de discriminação e a segunda assegura o ingresso no serviço público de pessoas portadoras de diabetes ${ }^{(16)}$.

O homem é ser-no-mundo... O modo como ele considera a condição humana fará de sua vida uma orquestra afinada entre labor, trabalho e família, como também poderá desafiná-la utilizando notas musicais que o destruirão em suas relações afetivas, econômicas e sociais(17). Diante do exposto, visualizamos que o cuidador 6 elucida que a convivência com o Diabetes mellitus em seu lar afeta suas relações sociais.

[...] Quando eu saio, eu tenho que voltar umas 8 horas da noite porque ele fica falando: vamos embora vai, esta na hora da insulina, só se ele tiver muito entretido pra ele não ficar falando, senão ele fica buzinando na minha orelha. $(\mathrm{Cl} 6)$

O ser-com o outro, na doença, pode tornar-se uma participação significativa quando expressa solicitude, ou seja, manifestação de consideração e paciência com o outro. Ora, uma das finalidades do profissional de saúde é justamente esta: cuidar do outro que implica na coexistência e na participação ativa no processo da doença. Contudo, apreendemos, na linguagem do cuidador 4, que ele vivenciou a ausência dessas demonstrações, o que se caracteriza como um cuidado inautêntico desses profissionais, mantendo-se alheio aos sentimentos do outro e, principalmente, não tendo compaixão da situação vivenciada pelo cuidador. Sobre isto, falaram para nós, de perto, as seguintes palavras: é necessário ter compaixão, porque sem esta simplesmente passamos pelas emoções, não importa o quanto sejamos tecnicamente habilidosos. Como enfermeira, é difícil compreender como alguém está se sentindo, no entanto, é possível tentar imaginar a pessoa nessa condição colocando-se no seu lugar ${ }^{(18)}$.

[...] Tentei pegar a alantus na 15a muito mal atendida pelo farmacêutico, que disse que isso era um processo demorado, que minha filha não era a única que precisava, que tinha problemas mais sérios, com isso, nós compramos, mas não é barato, mas por ela vamos fazer qualquer sacrifício. O ano passado fiz convênio particular, para ver se eu conseguia pegar alantus, mas não consegui, parei de pagar. Sabe é muito complicado, pois, no Posto de Saúde a gente não tem orientação, por convênio também não, temos então que ir se virando como pode. $(\mathrm{Cl} 4)$

\footnotetext{
Vivenciando a necessidade de compartilhar seu pesar
} 
Ao se arrolar em seu Eigenwelt, ou mundo pessoal, o ser-no-mundo toma consciência de si mesmo, atribuindo significados às situações inesperadas que veem ao seu encontro. Atentandonos à linguagem do cuidador 6 , percebemos que ao receber a confirmação do diagnóstico de seu filho, exprime o desejo de ser cuidado, amado, compreendido e, principalmente, de compartilhar suas preocupações e seus medos. Assim, busca conforto em seu companheiro, no entanto, demonstra pesar ao constatar que sua dor não é compreendida, pois deixou transparecer, em sua fala, que ela negligenciou os cuidados com filho.

[...] Na hora que eu vi o resultado eu estava sozinha, liguei para o pai dele, ele falou: vai fazer o que agora? Tem que cuidar. Já está com a doença, tinha que ter prevenido antes, agora tem que cuidar para o outro não ter. Mais é complicado. Nos primeiros dias eu ficava acordada para ver se estava tudo bem. (CI6)

O viver do homem caracteriza-se por um constante estar com os outros e com as coisas que fazem parte do mundo ao seu redor. Assim, relacionar-se com os outros faz parte de nosso existir, tornando-nos capazes de tocar e nos deixar tocar por outros. A essa abertura do homem, ao relacionar-se com o mundo (Ser-em), denomina-se de claridade do Ser-aí, sendo basicamente nessa claridade que se torna possível qualquer visão. Para o filósofo, a visão é um modo fundamental de abertura do Ser-no-mundo, ou seja, é um modo próprio de apropriação genuína dos entes com os quais o Ser-aí pode se comportar e assumir suas possibilidades ontológicas essenciais ${ }^{(6)}$.

Pois, o estresse por cuidar em cuidar de uma criança com diabetes pode exacerbar quaisquer problemas psicológicos, sociais ou financeiros que a família possa já estar vivenciando. Assim, procurar apoio é essencial para o bem-estar de todos os membros da família, porque o diagnóstico do diabetes muda para sempre a família e sua dinâmica.

As manifestações, a seguir, demonstram que alguns cuidadores sentem-se aliviados ao compartilhar sua facticidade com outros entes, principalmente, ao constatarem que eles experienciam as mesmas dificuldades.

[...] Todas as crises que ele tem eu corro para alguém. Eu nunca fico sozinha. ( $\mathrm{Cl} 1$ )

[...] Tem uma moça que trabalha comigo lá que a filha dela também tem, o que eu passei no começo ela também passou, eu conversei bastante com ela ai nós lemos bastante coisa, tem bastante estudo já em relação a isso. $(\mathrm{Cl} 2)$

[...] Eu não tinha nenhuma explicação, pois não tinha com quem conversar, minha família mora toda no estado de São Paulo. Chegava no hospital angustiada, mas me confortava porque tinha outras mães com problemas mais complicados que o meu, mas, ao mesmo tempo, não sabia como iria cuidar da minha filha, apesar de que, tinha uma enfermeira lá que também tinha uma filha diabética, foi onde ela me passou muitas informações sobre a alimentação, porque cada médico que vinha falava uma coisa diferente. $(\mathrm{Cl} 4)$

$\mathrm{Na}$ linguagem do cuidador 6, apreendemos que, a família em sua percepção, revela-se como cuidadores autênticos, assumindo e compartilhando com ele as dificuldades em cuidar de seu ente querido, buscando formas de amenizar seu sofrimento, uma vez que, sendo o Diabetes mellitus uma patologia que traz temor à pessoa, observamos que o cuidador sente-se aliviado em estar com a família.

[...] Tive bastante apoio da minha mãe, do meu pai não, a família da minha mãe é bastante unida. Acontece alguma coisa fica todo mundo junto, o pai dela não ajudava em nada e na época eu não trabalhava, dependia da minha mãe. $(\mathrm{Cl} 6)$

O Ser que adoece e sua família não estão isolados, vivendo sem os outros, pois estes são copresenças de seu existir no mundo. Nesse pensar, averiguamos na fala do cuidador 6 , que a aceitação por parte da família, a união, a solidariedade, conseguem fazer milagres(19), pois aviva-lhe segurança e bem estar.

\section{A importância da espiritualidade para o entendimento da situação}

Na analítica do Ser-aí, Heidegger considera a angústia uma possibilidade ontológica que revela o horizonte ôntico do homem como ente. Não obstante, esse mostrar-se do Ser-aí advém de sua abertura ao mundo, com disposição e compreensão, pois a angústia surge do próprio homem, à medida que este se percebe um ser-lançado-para-a-morte. O filósofo observa, ainda, que a angústia não desentranha um ser aflito e conturbado com o temor, ao contrário, libera o Ser-aí de suas possibilidades nulas, tornando-o livre para assumir as possibilidades concretas de seu existir. É na angústia que se revela o abandono do homem a si mesmo. Encontrando-se face a face com sua terrível liberdade de ser ou não ser, de permanecer na inautenticidade ou lutar pela posse de si mesmo ${ }^{(6)}$.

Não obstante, no discurso existencial heideggeriano, se, por um lado, o ser-no-mundo relaciona a angústia a um malum futurum, visualiza na esperança o desenvolver de um bonnum futurum, pois a esperança traz ao ser humano a força necessária para emergir de sua angústia e vislumbrar novas possibilidades. "Aquele que tem esperança se carrega, por assim dizer, a si mesmo para dentro da esperança, contrapondo-se ao que é esperado"(6). 
Nesse entender, compreendemos a partir da linguagem dos cuidadores que, ao assumirem seu estar-no-mundo com um filho diabético, buscam novos horizontes para reconstruir suas vidas. Nesse contexto, a fé torna-se importante ferramenta para o enfrentamento do diagnóstico e tratamento do Diabetes mellitus. A fé ou a busca pela ajuda Divina faz com que a pessoa ; projete-se à busca de recursos na luta contra a doença. Portanto, sentimos que para eles, refletir, orar ou rezar, é uma maneira de se aproximar de Deus e de ter forças para suportar as vicissitudes impostas pela doença.

[...] Meu Deus, só Deus, ele e a minha coragem. Mas tem hora que a gente enfraquece, Deus do céu, é que eu rezo muito. $(\mathrm{Cl} 3)$

[...] A gente tem muita fé em Deus, vou pouco à igreja, mais minhas orações tem muita fé em Deus, que ela vive 24 horas na minha cabeça, eu posso estar onde for, mais meu pensamento é nela. ( $\mathrm{Cl} 5$ )

A experiência mística revelaria ao homem a existência de Deus e levaria à descoberta dos conhecimentos necessários, eternos e imutáveis existentes na alma. Implica, pois, a concepção de um ser transcendente que daria fundamento à verdade. Deus, assim encontrado, é, ao mesmo tempo, uma realidade interna e transcendente ao pensamento ${ }^{(20)}$.

\section{REFLEXÕES SOBRE O ESTUDO}

Ao serem interrogados sobre sua experiência de cuidar de uma criança diabética, os cuidadores informais expressaram suas percepções acerca deste fenômeno, dentro de um tempo e espaço no qual estão inseridos.

Nos relatos, examinamos que vivenciar esta situação é um fardo difícil de ser abarcado de imediato pelos cuidadores, pois a doença enquanto possibilidade do cotidiano humano surge diante deles aniquilando todos seus sonhos, esperanças e, envolvendo-os em um sentimento de estranheza radical, assim, o ser humano sente-se completamente desorientado.

$\mathrm{E}$, neste estado, os cuidadores exprimem sentirem-se angustiados ante o sofrimento a ser experienciado. Pois, o impacto do Diabetes mellitus, em seus lares, é tão severo que pode causar uma crise de adaptação de enfrentamento pela família, fazendo-os viver em estado de incerteza entre o vigor de ter sido feliz com seu ente querido e a tristeza do porvir. Essa condição insula-os em si mesmos e, esses seres passam a viver em um estado de decaimento, não visualizando a possibilidade de transcender o instante vivido, deixando-se guiar pela situação e, em muitos momentos, sentem o desejo de compartilhar a dor que trazem no âmago de seus seres, mas sentem-se sozinhos.

Nas linguagens dos entrevistados, distinguimos que as diversas fases que surgem no enfrentamento da descoberta do diabetes, em seu ente próximo, não seguem uma ordem pré-estabelecida, podendo ter uma duração variável, uma substituição ou interação das fases descritas acima, ou seja, não obedecem a uma simples ordem de causa e efeito, ela é o resultado de ações e reações da pessoa em seu meio social, em relação ao seu passado, presente e futuro. Portanto, devemos estar atentos ao modo como o portador de Diabetes e seus familiares sentem, enfrentam e interpretam o diabetes e 0 seu diagnóstico.

Nessa perspectiva, observamos que as dificuldades em cuidarem de seus filhos não são vislumbradas pelos Seres cuidadores, uma vez que o mundo vivenciado por eles em seu existir cotidiano permanece esquecido, enredado em seus conflitos e inquietações, e que, na maioria das vezes, eles não são percebidos pelos entes ao seu redor. Assim, é de vital importância que a conduta do Ser-aí cuidador seja cuidar destes seres a partir das percepções que este tem da situação vivida, e não somente a partir de sua própria experiência. Pois esta, na maioria das vezes, está envolvida pelo contato que o cuidador mantém com o mundo circundante em que vive e no qual a humanidade muitas vezes é esquecida.

\section{REFERÊNCIAS}

1. Costa AA, Neto JSA. Manual de diabetes: Educação, alimentação, medicação e atividades físicas. 5th ed. São Paulo: Sarvier Editora de Livros Médicos Ltda; 2009.

2. Sociedade Brasileira de Diabetes. Cresce incidência de diabetes em criança e adolescentes [Internet]. Corumbá: Prefeitura Municipal de Corumbá; 2007 Nov 14. [cited 2009 agu 16]. Available from: http://www.corumba.ms.gov.br/modules/news/articl e. php?storyid $=2634$

3. Secretaria de Atenção à saúde, Ministério da Saúde. Diretrizes e recomendações para o cuidado integral de doenças crônicas não- transmissíveis. Promoção da saúde, vigilância, prevenção e assistência [Internet]. Brasília: Ministério da saúde; 2009 [cited 2009 agu 16]. Available from: http://portal.saude.gov.br/portal/arquivos/pdf/volum e8livro.pdf

4. Silva MAD. Quem Ama Não Adoece. São Paulo: Best Seller; 2006.

5. Freitas FV, Sabóia VM. Vivências de adolescentes diabéticos e contribuições da prática educativa da enfermeira. Rev. enferm. UERJ . 2007; 15(4): 569-73.

6. Heidegger M. Ser e Tempo. Rio de Janeiro: Editora Universitária São Francisco; 2006.

7. Martins J. Ontologia de Heidegger. In: Martins J, Bicudo MAV. Estudos sobre fenomenologia e educação. São Paulo: Centauro; 2006. p. 43-53.

8. Ministério do Desenvolvimento Social e Combate à Fome. Lei no 8.069, de 13 de junho de 1990 Estatuto da Criança e do Adolescente. Brasília 
(Brasil): Ministério do Desenvolvimento Social e Combate à Fome; 1990.

9. Josgrilberg RS. O método fenomenológico e as ciências humanas. In: Castro DSP, Pokladek DD, Azar FP, Piccino JD, Josgrilberg RS. Fenomenologia e análise do existir. São Paulo: Sobraphe 2000. p. 7593.

10. Sales CA, Alves NB, Vrecchi MR, Fernandes J. Concepções das mães sobre os filhos prematuros em UTI. Rev. Bras. Enferm. 2006; 59(1):20-4.

11. Crosseti MGO. Processo de cuidar: uma aproximação à questão existencial na enfermagem [thesis]. Florianópolis: UFSC; 1997. 177 p.

12. Zanetti ML, Mendes IAC. Análise das dificuldades relacionadas às atividades diárias de crianças e adolescente com diabetes mellitus tipo 1: depoimentos de mães. Rev Latino-am Enfermagem. 2001;9(6): 25-30.

13. Nunes MDR, Dupas G, Ferreira NMLA. Diabetes na infância/adolescência: conhecendo a dinâmica familiar. Rev. Eletr. Enf. [Internet]. 2007 [cited 2009 agu 16];9(1):119-30. Available from: http://www.fen.ufg.br/revista/v9/n1/v9n1a09. htm.

14. Gouveia GR, Bruno LPC. Alimentação equilibrada - a base para controle do diabetes mellitus [Internet].São Paulo: Diabetenet; 2004 Abr 25 [cited 2009 agu 16]. Available from: http://www. diabetenet.com. br/conteudocompleto.asp ?idconteudo=2247.

15. American Diabetes Association. Care of children with diabetes in the school and Day care setting. Diabetes Care [Internet]. 2003 [cited 2009 agu 16];26(Suppl 1):S131-5. Available from: http://care.diabetesjournals.org/content/26/suppl_1/ s131.full.pdf

16. Ministério do Desenvolvimento Social e Combate à Fome. Lei no 8.069, de 13 de junho de 1990. Estatuto da Criança e do Adolescente. Brasília (Brasil): Ministério do Desenvolvimento Social e Combate à Fome; 1990.

17. Santos DL, Pokladk DD. Fenomenologia e ciência da saúde. In: Castro DSP, Pokladek DD, Àzar FP, Piccino JD, Josgrilberg RS. Existência e saúde. São Bernardo do Campo: UNESP; 2002. p. 163-70.

18. Pessini L. A filosofia dos cuidados paliativos: uma resposta diante da obstinação terapêutica. O mundo da saúde. 2003; 27(1): 15-32.

19. Chartuni A. Adaptação ao diabetes: uma criança feliz. Jornal "O amanha é hoje" [Internet]. 2002 [cited 2009 mai 22]. Available from: http://www. diabete.com.br/biblio/criancas3.html 20. Agostinho S. Os pensadores. São Paulo: Círculo do Livro; 1996.

Artigo recebido em 22.09.08.

Aprovado para publicação em 03.06.09.

Artigo publicado em 30.09.09. 